\title{
ADDICTION
}

\section{Cannabis against heroin?}

Relapse after addictive-drug withdrawal is a big societal problem and is thought to be induced by environmental cues. The identification of treatments that attenuate cue-induced relapse is one aim of addiction research. This study showed that the non-psychotropic component of cannabis, cannabidiol (CBD), antagonizes cue-induced drug-seeking behaviour after heroin withdrawal and discovered that it acts by normalizing glutamate and cannabinoid receptor expression levels in neurons that are involved in the drug-seeking behaviour.

The authors investigated the effect of CBD on the maintenance, extinction and relapse of heroin seeking in rats. Animals which were

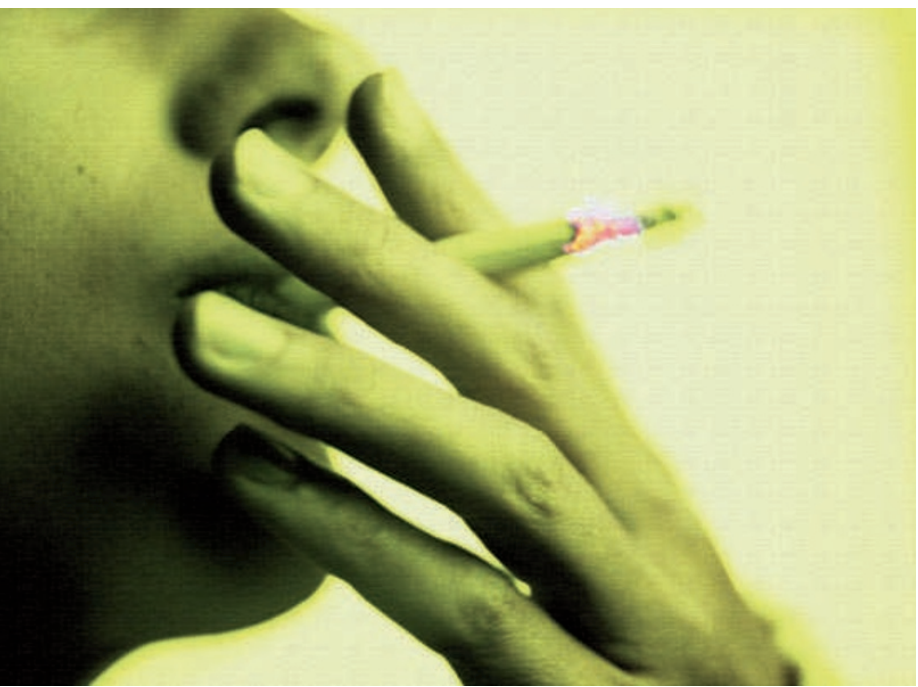

steadily self-administering heroin by pressing a lever in a designated chamber that contained a light as an environmental cue did not change their heroin intake behaviour after treatment with CBD. After 14 days of drug abstinence, rats were re-exposed to the self-administration chamber and stimulus light cue or to the light cue alone. The drug-seeking behaviour of rats that had been treated with CBD 24 hours prior to the behavioural test was attenuated. It is noteworthy that during these tests the rats did not have access to heroin after lever pressing, as that would have reinstated their drug dependence. The results suggest that CBD specifically attenuated drugseeking behaviour in response to environmental cues.

The striatum is thought to be involved in reward behaviour and habit formation. The authors found that mRNA and protein levels of the cannabinoid receptor $\mathrm{CB}_{1} \mathrm{R}$ were significantly increased in the mesolimbic system (specifically the nucleus accumbens (NAc) and dorsal striatum) of heroin-addicted rats but not in the dorsolateral division of the striatum (which receives primarily sensorimotor cortical input). CBDtreated addicted rats had levels of $\mathrm{CB}_{1} \mathrm{R}$ similar to control animals. These findings are consistent with previous studies which showed that inhibition of $\mathrm{CB}_{1} \mathrm{R}$ blocks cue-induced drug-seeking behaviour.
Drug-seeking behaviour has also been linked to dysregulation of glutamate and opioid transmission. The authors found that the expression of AMPA ( $\alpha$-amino-3-hydroxy5-methyl-4-isoxazole propionic acid) GluR1 receptors, which are strongly linked to drug-seeking behaviour, was downregulated in the NAc core and the medial and lateral shell in heroin-addicted rats. 24 hours after CBD administration, GluR1 protein expression was normalized in the NAc core and medial shell.

This study reveals unexpected properties of CBD, namely the selective and prolonged inhibition of cue-induced drug seeking. These characteristics of CBD thus contrast with those of the other main constituent of cannabis, the psychoactive $\Delta^{9}$-tetrahydrocannabinol (THC), which has been associated with addiction vulnerability. CBD could therefore be exploited for the development of drugs to combat relapse.

Claudia Wiedemann

$$
\begin{aligned}
& \text { ORIGINAL RESEARCH PAPER Ren, Y. et al. } \\
& \text { Cannabidiol, a nonpsychotropic component of } \\
& \text { cannabis, inhibits cue-induced heroin seeking } \\
& \text { and normalizes discrete mesolimbic neuronal } \\
& \text { disturbances. J. Neurosci. 29, 14764-14769 (2009) } \\
& \text { FURTHER READING Kauer, J. A. \& Malenka, R. C. } \\
& \text { Synaptic plasticity and addiction. Nature Rev. } \\
& \text { Neurosci. 8, 844-858 (2007) | Murray, R. M., } \\
& \text { Morrison, P. D., Henquet, C. \& Di Forti, M. } \\
& \text { Cannabis, the mind and society: the hash } \\
& \text { realities. Nature Rev. Neurosci. 8, } \\
& \text { 885-895 (2007) | Kalivas, P. W. The glutamate } \\
& \text { homeostasis hypothesis of addiction. Nature Rev. } \\
& \text { Neurosci. 10, 561-572 (2009) }
\end{aligned}
$$

